\title{
Cloning of full genome sequence of hepatitis E virus of Shanghai swine isolate using RACE method Quan Shen ${ }^{1,2}$, Wen Zhang1, Xiangrong $\mathrm{CaO}^{2}$, Jing Mou${ }^{1}$, Li Cui ${ }^{1}$ and Xiuguo Hua*1
}

\author{
Address: ${ }^{1}$ School of Agriculture and Biology, Shanghai JiaoTong University, 800 Dongchuan Road, Shanghai 200240, PR China and ${ }^{2}$ School of \\ Life Science, Nanjing Normal University, 1 Wenyuan Road, Nanjing 210097, PR China \\ Email: Quan Shen - njnushenquan@yahoo.com.cn; Wen Zhang - z0216wen@njnu.edu.cn; Xiangrong Cao - caoxiangrong@njnu.edu.cn; \\ Jing Mou - shenquanfly@yahoo.com; Li Cui - lcui@sjtu.edu.cn; Xiuguo Hua* - hxg@sjtu.edu.cn \\ * Corresponding author
}

Published: 9 October 2007

Virology Journal 2007, 4:98 doi:10.1186/1743-422X-4-98

This article is available from: http://www.virologyj.com/content/4/I/98

(c) 2007 Shen et al; licensee BioMed Central Ltd.

This is an Open Access article distributed under the terms of the Creative Commons Attribution License (http://creativecommons.org/licenses/by/2.0), which permits unrestricted use, distribution, and reproduction in any medium, provided the original work is properly cited.
Received: 2 August 2007

Accepted: 9 October 2007

\begin{abstract}
Genotype 4 hepatitis E virus (HEV) was reportedly transmitted freely between humans and swine in eastern China. The full-length genomic sequence of Shanghai swine isolate (SH-SW-zsI) recovered from feces sample of a pig which was infected with HEV RNA positive swine serum was determined using RT-PCR and RACE (Rapid Amplification of cDNA Ends) methods. The full genome of the SH-SW-zsI isolate was 7265 nucleotides in length and phylogenetic analysis indicated that this isolate belonged to genotype 4. Comparison of the 3' UTR sequence with the corresponding regions of other $38 \mathrm{HEV}$ strains from different region revealed that the Shanghai swine isolate is $21-49$ bp longer than the other stains.
\end{abstract}

\section{Introduction}

Hepatitis $\mathrm{E}$ is an important public health disease in many developing countries of Asia and Africa and also occurs sporadically in some industrialized countries [1-4]. The disease mainly affects young adults and has a relatively high mortality of up to $25 \%$ in affected pregnant women [1]. The main mode of transmission of hepatitis $E$ virus (HEV) is fecal-oral route, primarily through contaminated water supplies [1]. HEV is single-stranded, positive-sense RNA virus without an envelope [5]. The genome of HEV is approximately $7.2 \mathrm{~Kb}$ and consists three open reading frames (ORF1-3) [6]. ORF1 locates at the 5 ' end of genome and encodes non-structural proteins, including the methyltransferase, protease, helicase and RNAdependent RNA polymerase (RdRp) [7]. ORF2 maps to the 3 ' terminus and encodes for a major structural protein, and ORF3 overlaps both and encodes a thus far unknown function [6]. Based on sequence analysis, HEV sequences have been classified into four major genotypes (1-4). Genotype 1 is the main cause of hepatitis $\mathrm{E}$ in developing countries in Asia and Africa, and genotype 2 has been documented in Mexico and Nigeria. Genotype 3 or 4 have been described in the United States, European countries, China, Taiwan, and Japan $[8,9]$. The virus is also prevalent in swine, and isolates from swine are genetically closely related to that from humans [10-12]. Lots of researches showed that genotype 4 and genotype 1 were the major genotype in China, recently genotype $3 \mathrm{HEV}$ was reported in swine of Shanghai suburb [13]. For the further research, such as genomic characteristics and phylogenetic analysis, the full genome of the isolate which was proved prevalent in Shanghai swine was determined in the current study. 


\section{Materials and methods Samples}

132 serum samples of swine were collected from Shanghai suburb in China. These samples were tested for HEV RNA, using reverse transcriptase-polymerase chain reaction (RTPCR). One HEV RNA positive swine serum sample was used for experimental infection of pigs [14]. HEV RNA positive swine fecal samples were stored as $10 \%$ suspension in aliquots at $70^{\circ} \mathrm{C}$. About $10 \mathrm{~g}$ of HEV RNA positive fecal sample was converted to $10 \%(\mathrm{w} / \mathrm{v})$ suspensions in PBS (0.01 M, pH 7.2-7.4, added 0.1\% DEPC) for determining the full genomic sequence of $\mathrm{HEV}$.

\section{Viral RNA extraction}

One hundred microlitre of fecal suspensions was mixed with $1 \mathrm{ml}$ of trizol (invitrogen, USA). The mixture was homogenized and incubated for $5 \mathrm{~min}$ at room temperature. Two hundred microlitre of chloroform was added and the mixture was vigorously shaken for $15 \mathrm{~s}$ and incubated at room temperature for $3 \mathrm{~min}$. The aqueous phase was transferred to a fresh microfuge tube after centrifugation at $12000 \mathrm{~g}$ for $15 \mathrm{~min}$ at $4^{\circ} \mathrm{C}$. Five hundred microlitre of isopropyl was added and the mixture was incubated for $15 \mathrm{~min}$ at room temperatures. Then centrifuging at 12 $000 \mathrm{~g}$ at $4^{\circ} \mathrm{C}$ for $15 \mathrm{~min}$. After discarding the supernatant, RNA pellet was washed with $1 \mathrm{ml} 75 \%$ ethanol. The RNA pellet was Dried at room temperature for 5 min after centrifuging at $5000 \mathrm{~g}$ for $5 \mathrm{~min}$ at $4^{\circ} \mathrm{C}$ and Discarding the supernatant. RNA sample was dissolved with 20 ul DEPCtreated water and used to reverse transcription immediately.

\section{PCR amplification}

Full-length primers: 18 sets of degenerate primers were designed based on a multiple sequence alignment of entire genome from isolates AY594199, DQ279091, DQ450072 and AB108537 (table 1). Reverse transcription was carried out at $42^{\circ} \mathrm{C}$ for $1 \mathrm{~h}$ with $1 \mathrm{ul}$ (200 units) of AMV Reverse Transcriptase (TakaRa, Japan) and $1 \mathrm{ul}$ (25 mM) of external antisense primer. The first round PCR was carried using $10 \mathrm{ul}$ of the synthesized cDNA and an external set of forward and reverse primers with Ex Taq DNA polymerase (TakaRa, Japan). A nested PCR was carried out with internal primer set and $5 \mathrm{ul}$ of the first PCR product. The PCR parameters of all amplification reactions included an initial incubation at $95^{\circ} \mathrm{C}$ for $9 \mathrm{~min}$, followed by 39 cycles of denaturation at $94^{\circ} \mathrm{C}$ for $1 \mathrm{~min}$, annealing for $1 \mathrm{~min}$ at a temperature varied according to the Tm of different primers, and extension at $72^{\circ} \mathrm{C}$ for 1.5 min, with a final incubation at $72^{\circ} \mathrm{C}$ for $7 \mathrm{~min}$. The resulting PCR products were excised from agarose gel and purified using the Axyprep DNA Gel Extraction Kit (AXYGEN, USA). The purified PCR products were ligated into PMD18-T vector (TakaRa, Japan) using T4 DNA ligase (TakaRa, Japan) at $16^{\circ} \mathrm{C}$ overnight. The recombinant plas- mid was transformed into DH $5 \alpha$ competent Escherichia coli cells (TakaRa, Japan). Plasmids containing the insert fragment were identified by PCR. Three of the positive clones were sequenced.

\section{5'RACE}

The 5'RACE was carried out with the 5-Full RACE Core Set (TaKaRa, Japan) kit following the manufacture's instructions. Briefly, 1st strand cDNA was Synthesized by reverse transcription using 5'end-phosphorylated RT Primer which was specific to the swine HEV (5'-p-GTCATRCCRTGGCG-3'). The PCR reaction mixture was incubated for 2 min at $94^{\circ} \mathrm{C}$ followed by 35 amplification cycles, comprising denaturation at $94^{\circ} \mathrm{C}$ for $30 \mathrm{~s}$, annealing at $65^{\circ} \mathrm{C}$ for $30 \mathrm{~s}$ and extension at $72^{\circ} \mathrm{C}$ for $30 \mathrm{~s}$. The reaction was extended for another $7 \mathrm{~min}$ at $72^{\circ} \mathrm{C}$ to insure the full extension. Fifteen ul of 1 st Strand cDNA was treated with RNase $\mathrm{H}$ in a total $75 \mu \mathrm{l}$ reaction mixture containing $15 \mathrm{ul}$ of Hybrid RNA Degeneration Buffer for $1 \mathrm{~h}$ at $30^{\circ} \mathrm{C}$. The mixture was then precipitated at $-20^{\circ} \mathrm{C}$ for $30 \mathrm{~min}$, being added $100 \mathrm{ul}$ of $\mathrm{H}_{2} \mathrm{O}$ and $500 \mathrm{ul} 100 \%$ ethanol. The supernatant was discarded and the pellet was washed with $75 \%$ ethanol after centrifuging at $12000 \mathrm{~g}$ for $5 \mathrm{~min}$. The pellet was dissolved with 8 ul of RNA (ssDNA) Ligation Buffer and 12 ul of $\mathrm{H}_{2} \mathrm{O}$ after dried at room temperature for $5 \mathrm{~min}$. $20 \mathrm{ul}$ of $40 \%$ PEG-6000 and $1 \mathrm{ul}$ of ligase were added and incubated at $16^{\circ} \mathrm{C}$ overnight. Fifteen microliters of circled cDNA was then used as template for nested PCR using ExTaq DNA polymerase (TaKaRa, Japan)with two sets of primers: 5'-CGGAGTTGGCCGCTGCTAGAG$3^{\prime}$ (external forward primer, nucleotide position numbers 104 to 84), 5'-TGTACT(G)TTTGCTGCTGAGAC-3'(external reverse primer, nucleotide position numbers 482 to 501), 5'-ATTGGGTGATTCCACAG(A)AACCTC-3'(internal forward primer, nucleotide position numbers 225 to 203), and 5'-ATCCACAAC(T)GAGCTT(C)GAGCAG3 '(internal reverse primer, nucleotide position numbers 236 to 256). The PCR reaction mixture was incubated for 2 min at $94^{\circ} \mathrm{C}$ followed by 35 amplification cycles, comprising denaturation at $94^{\circ} \mathrm{C}$ for $30 \mathrm{~s}$, annealing at $65^{\circ} \mathrm{C}$ for $30 \mathrm{~s}$ and extension at $72^{\circ} \mathrm{C}$ for $30 \mathrm{~s}$. The reaction was extended for another $7 \mathrm{~min}$ at $72^{\circ} \mathrm{C}$ to insure the full extension. The final PCR product was analyzed on $20 \mathrm{~g} / \mathrm{L}$ agarose gel.

\section{3'RACE}

The 3'RACE was carried out with the TaKaRa RNA PCR Kit (TaKaRa, japan) following the manufacture's instructions. Brifely, ten microliters of the HEV RNA was used as template to synthesize cDNA with AMV Reverse transcriptase for $1 \mathrm{~h}$ at $42^{\circ} \mathrm{C}$. The external reverse primer (HE17A) which has a poly (T) tract was used to prime the cDNA synthesis. The cDNA was then amplified by nested PCR with the external forward primer (5'-CGCTCACTACTATCCAGCAG-3', nucleotide position numbers 6763-6782) 
Table I:

\begin{tabular}{|c|c|c|}
\hline Primer name & Nucleotide position & Nucleotide sequence $\left(5^{\prime}-3^{\prime}\right)$ \\
\hline HEOES & $104-84$ & CGGAGTTGGCCGCTGCTAGAG \\
\hline HEOEA & $482-501$ & TGTACT(G)TTTGCTGCTGAGAC \\
\hline HEOIS & $225-203$ & ATTGGGTGATTCCACAG(A)AACCTC \\
\hline HEOIA & $236-256$ & ATCCACAAC(T)GAGCTT(C)GAGCAG \\
\hline HEIES & $11-32$ & TATGTGGTCGACGCCATGGAGG \\
\hline HEIEA & $528-509$ & GCCCTTTATTCACTGCACGA \\
\hline HEIIA & $573-554$ & ATACCGTGGCGAGCCATTGC \\
\hline HE2ES & $482-501$ & TGTACTTTTGCTGCTGAGAC \\
\hline HE2EA & $956-975$ & ACAGGGACGGCATGAAATGT \\
\hline HE2IS & $437-454$ & CTTCCACCTGT(C)T(C)GAT(C)CGG \\
\hline HE2IA & $1000-983 s$ & $\operatorname{AAGCATA}(\mathrm{G}) \mathrm{AGCCTGTCCCA}$ \\
\hline HE3ES & $67 \mid-692$ & CGTGCA(T)GTG(A)ATTACATAT(C)GAGG \\
\hline HE3EA & $1336-1317$ & $\operatorname{CCACCGG(T)CGAA(G)CACTGG(A)GCAT~}$ \\
\hline HE3IS & $742-762$ & GATCCGT(G)ACC(G)ACT(C)AAGGTCAC \\
\hline HE3IA & $13 \mid 4-1293$ & AACTG(C)CAA(G)CTGA(G)CGA(G)CCAGGGA \\
\hline HE4ES & $984-1005$ & GGGACAGGCTTATGCTTTTTGG \\
\hline HE4EA & $1528-1508$ & TGCCTCATTATCATAACCCTG \\
\hline HE4IS & $956-975$ & ACGTTTCATGCCGTCCTGT \\
\hline HE4IA & $1703-1684$ & GGCCGTCG(A)GCA(G)TCAGAG(A)ACC(T) \\
\hline HE5ES & $|33|-1348$ & CGGTGGT(C)TG(A)TCTGCC(T)GGC \\
\hline HE5EA & $1792-1746$ & GTTGAG(A)AAGGTT(C)TTATTG(A) \\
\hline HE5IS & $1310-1329$ & C(G)AGTTT(C)TATGCCCAGTGTCG \\
\hline HE5IA & $1803-1785$ & GACAG(A)C(G)ACATAC(T)TGCTCT(C)G \\
\hline HE6ES & $1508-1528$ & CAGGGT(C)TATGAT(C)AAT(C)GAGGC \\
\hline HE6EA & $2529-2510$ & GGGAAC(A)CGT(C)TGA(G)TAGAAT(A)GC \\
\hline HE6IS & $1679-1700$ & GTTGAG(A)GTC(T)TCTGAT(C)GCC(T)GACG \\
\hline HE6IA & $2477-2457$ & GGTTA(G)GAT(C)GCATTA(G)ACCAGCC \\
\hline HE7ES & $2028-2048$ & TGTGGTAC(T)T(C)AC(T)CCTGAGGGGC \\
\hline HE7EA & $2144-2123$ & CTCTACACT(C)CGG(T)ACCTGGTCGG \\
\hline HE7IS* & $2830-2850$ & GTAAGGGCTGGAAGGGTGGGC \\
\hline HE7IA* & $2913-2893$ & ACTTCAGTGGCGGAGTCTAAC \\
\hline HE8ES & $2753-2772$ & GCCTGGGAACGTAACCACCG \\
\hline HE8EA & $3366-3347$ & GTCTGGATC(T)TTT(C)GGGTACGC \\
\hline HE8IS & $2714-2733$ & GCCGGC(T)ATATATAAGGTC(A)CC \\
\hline HE8IA & $3438-3416$ & GCCTGGGTG(A)AAT(C)ACCAA(G)CTTCT(C)G \\
\hline HE9ES & $3209-3228$ & GGTGAC(T)CCC(T)AAT(C)AAT(C)AAATCCC \\
\hline HE9EA & $3948-3929$ & GGCGCTGCCATACGGCAGTG \\
\hline HE9IS & $3312-3334$ & GATGC(T)CCGGCG(A)GAT(C)GTCTGTGAG \\
\hline HEIIA & $3810-3791$ & GGTCGA(G)TGGCCAAGC(T)TCCTC \\
\hline HEIOES & $3764-3781$ & CAGTTTAGTGCT(C)TAC(T)CAG \\
\hline HEIOEA & $4432-44 \mid 3$ & ATCATTCTCAAAAÁCCTTÁC \\
\hline HEIOIS & $3587-3605$ & ACG(T)GAGAAG(A)TGTGTGGTG(C)G \\
\hline HEIOIA & $4518-4496$ & САСТСС $(T)$ TCCATGATTATACACTC \\
\hline HEIIES & $4290-4311$ & TGTTC(T)GGCCCA(C)TGGTTT(C)CGCGC \\
\hline HEIIEA & $4752-4733$ & CGATAGTCACTACAGAGCAC \\
\hline HEIIIS & $4355-4375$ & TATGGTGATGCA(G)TATGAG(A)GAC \\
\hline HEIIIA & $4736-4717$ & GCACAACAGAATCATCTCCC \\
\hline HEI2ES & $4607-4625$ & TGGAAGAAA(G)CAT(C)TCTGGTG \\
\hline HEI2EA & $5253-5233$ & CCGGTGGCGCGGGCAGCATAG \\
\hline $\mathrm{HEI} 2 \mathrm{IS}$ & $4496-4518$ & GAGTGTATAATCATGGAG(A)GAGTG \\
\hline HEI2IA & $5347-5366$ & GGTTGGATGAATATAGGGGA \\
\hline HEI3ES & $4977-4997$ & CGAATGTGGCTCAGGTTTGTG \\
\hline HEI3EA & $545 \mid-5431$ & GCCAAGCGGAACCGAGTGGAC \\
\hline HEI3IS & $5020-5039$ & CGGTGTTAGCCCTGGCTTGG \\
\hline HEI3IA & $5392-5371$ & GTTGGAATGTCGGATGCGAAGG \\
\hline HEI4ES & $5347-5366$ & ТССССТАТАТTСАТССАACC \\
\hline HEI4EA & $5956-5934$ & TGATTG(T)CGATAG(A)TGCAGGCGCTC \\
\hline HEI4IS & $5233-5252$ & CTATGCTGCCCGCGCCACCG \\
\hline HEI $4 \mathrm{IA}$ & $5980-5957$ & GAGGTCTCAACT(C)GAG(A)CGCCAA(G)CCC \\
\hline
\end{tabular}


Table I: (Continued)

\begin{tabular}{lll}
\hline HEI5ES & $5922-5942$ & GTGATT(C)CCTAGT(C)GAGCGCCTG \\
HEI5EA & $6415-6397$ & GTCGGCTCGCCATTGGCTG \\
HEI5IS & $5877-5896$ & ACTGATGTCCGC(G)ATC(T)CTTGT \\
HEI5IA & $6453-6433$ & CCTGCTGAGCATTCTCGACTG \\
HEI6ES & $6336-6357$ & CTC(A)CCGACAGAATTGATTTCGT \\
HEI6EA & $7005-6985$ & CAGAG(A)TGA(G)GGT(G)GCA(G)AGGACAC \\
HEI6IS & $6271-6292$ & TTGGTGAG(A)GTT(C)GGC(T)CGTGGTAT \\
HEI6IA & $7074-7054$ & CAGGGCAA(G)AG(A)ATCATCG(A)AAAG \\
HEI7ES* & $6763-6782$ & CGCTCACTACTATCCAGCAG \\
HEI7IS* & $6787-6808$ & CTAAGACCTTCTTTGTTCTGCC \\
HEI7A & & GTTTTCCCAGTCACGACTTTTTTTTTTTTTT \\
*: the primers & & \\
were designed & & \\
according to & & \\
isolate in this & & \\
study. & & \\
\hline
\end{tabular}

Position and nucleotide sequence of oligonucleotide primers for PCR. The nucleotide position is in accordance with the SH-SW-zsI isolate in this study. In the primer name, ES, EA, IS and IA mean "external sense", "external antisense", "internal sense" and "internal antisense", respectively. Letters in parentheses indicate degenerate bases.

and internal forward primer (5'-CTAAGACCTTCTTTGTTCTGCC-3', nucleotide position numbers 6787-6808) with ExTaq DNA polymerase (TaKaRa, Japan). The PCR reaction mixture was incubated for 2 min at $94^{\circ} \mathrm{C}$, followed by 35 amplification cycles comprising denaturation at $94^{\circ} \mathrm{C}$ for $30 \mathrm{~s}$, annealing at $65^{\circ} \mathrm{C}$ for $30 \mathrm{~s}$, and extension at $72^{\circ} \mathrm{C}$ for $30 \mathrm{~s}$. The reaction was extended for another $7 \mathrm{~min}$ at $72^{\circ} \mathrm{C}$ to ensure the full extension.

\section{Phylogenetic analysis}

Using Clustal $\times 1.8$, multiple alignments of nucleotide sequences was carried out. The phylogenetic status $\mathrm{SH}$ SW-zs1 isolate was assessed employing the software MEGA Version 2.1[15]. For analysis in MEGA, Jukescantor (JC) distance was utilized employing the Neighbor joining (NJ) algorithm. The reliability of different phylogenetic groupings was evaluated by using the bootstrap test (1000 bootstrap replication) available in MEGA. Accession numbers, designations and countries of origin of the full genome sequences employed for analysis in the present study were as follows:

Genotype 1: AF051830, Nepal; X99441, India; AF076239, India; AF459438, India; D10330, Burma; M73218, Burma; AF185822, Pakistan; X98292, India; L25595, China; M80581, Pakistan; AY230202, Morocco.

Genotype 2: M74506, Mexico.

Genotype 3: AP003430, Japan, human; AB091394, Japan, human; AB073912, Japan, swine; AY115488, Canada, swine; AF060668, US, human; AF082843, US, swine; AB089824, Japan, human; AB074918, Japan, human; AB074920, Japan, human.
Genotype 4: AB091395, Japan, human; AB097812, Japan, human; AB097811, Japan, swine; AB074915, Japan, human; AB074917, Japan, human; AJ272108, China, human; AB108537, China, human; AB161717, Japan, human; AB161718, Japan, human; AB161719, human; DQ450072, China, swine; AY594199, China, swine; DQ279091, China, swine; AB197673, China, human; EF077630, China, swine; AB197674, human.

Avian Hepatitis E virus (AY535004) was chosen as an outgroup. The sequence reported here has been deposited with GenBank accession no.: EF570133.

\section{Results \\ 3'RACE}

As shown in Figure 1, 3'RACE band of the expected size was obtained. The 3' terminus of this study had 93 nucleotides upstream of the polyA. The sequence of 3'UTR was: TTT ATT CTT CTT GTA CCT CCC CTT CGG TTC TGT TTC TTT TTA TTT CTC CTT TCT GCG TTC CGC GCT CAC TAC TAT CCA GCA GGA TCC ATG TTG. Comparison of the 3'UTR sequence with the corresponding regions of other $38 \mathrm{HEV}$ strains from different region of the world revealed that the Shanghai swine isolate is 21-49 bp longer than all the other stains (additional file).

\section{Analysis of Full-Length Genome of Shanghai Isolate}

The genomic length of the SH-SW-zs1 isolate was determined to be 7265 nucleotides (nt) excluding poly (A) tail at 3 ' terminus and contained three open reading frames (ORFs) similar to earlier reported human and swine HEV isolates. The genomic organization consisted of $5^{\prime}$ untranslated region (5'UTR) of 25 nt (1-25), ORF-1 of 5127 nt (26-5152), ORF-2 of 1983 nt (5190-7172), ORF-3 of 372 nt (5249-5520) and 3'UTR of 93 nt (71737265 ), followed by a poly (A) tail of 26 residues. The 


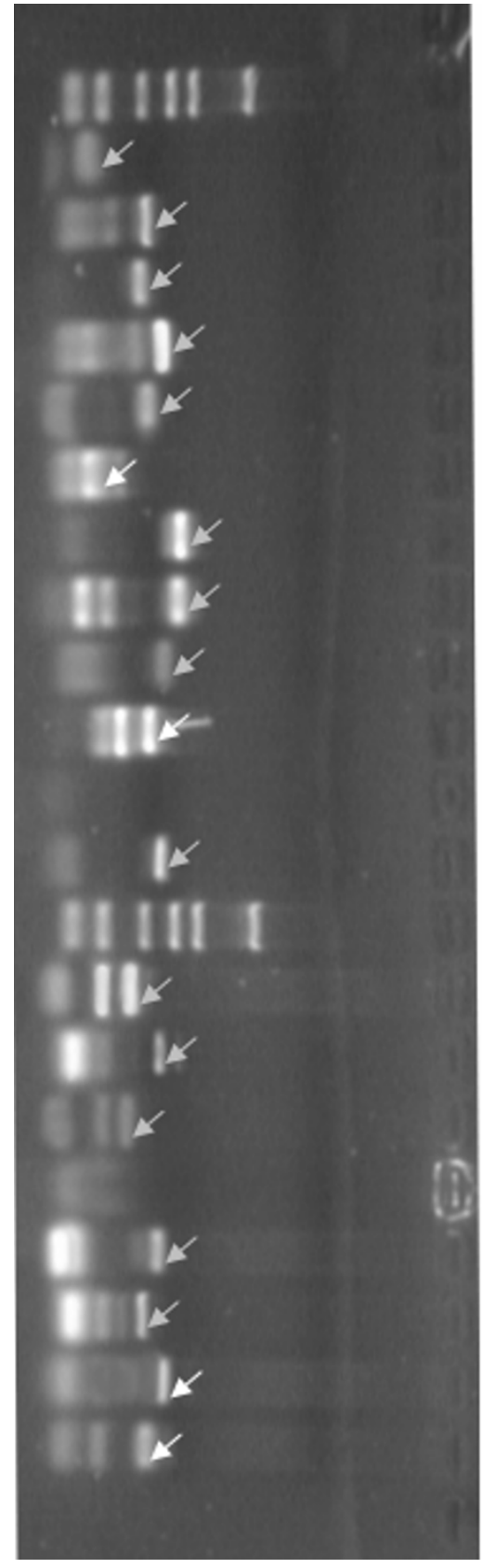

Marker

5' RACE, 188 bp

HE1, 562 bp

HE2, 493 bp

HE3, 572 bp

HE4, 523 bp

HE5, 461 bp

HE6, 798 bp

HE7, 727 bp

HE8, 623 bp

HE9, 498 bp

Negtive control

HE10, 668 bp

Marker DL2000

HE11, 381 bp

HE12, 646 bp

HE13, 372 bp

Negtive control

HE14, 609 bp

HE15, 493 bp

HE16, 669 bp

3' RACE

Figure I

RT-PCR products of SH-SW-zsI isolate. The right side shows the primers and the expected length of the fragment; Arrows display the aimed bands.

length of 5'UTR was same as that of other type 4 isolates and had nucleotide $\mathrm{G}$ at the extreme 5 ' end of the genome as other reported genotype 4 sequences. Whole genomebased phylogenetic analysis confirmed classification of Shanghai swine in genotype 4 (Fig. 2). The phylogenetic tree showed that genotype 4 could be divided into 3 main subgroups. SH-SW-zs1 isolate closely clustered with iso- late DQ450072 which was isolated from eastern China, and they shared $89.3 \%$ identity (with divergence of $11.3 \%$ ) with each other and represented a distinct subgroup among the genotype 4 isolates with a bootstrap value of $100 \%$.

\section{Discussion}

HEV is the major cause of enterically transmitted non-A, non- $\mathrm{B}$, non- $\mathrm{C}$ hepatitis and is responsible for significant morbidity and mortality in developing countries [16]. Outbreaks of hepatitis $\mathrm{E}$ have been described in Asia, Africa and Mexico [16-18], while sporadic cases have been reported in the United States, Japan and other developed countries [8]. It has been shown that HEV is a zoonotic virus $[19,20]$. Hitherto, the lack of an efficient cell-culture system for HEV has greatly hampered detailed analysis of the virus replication cycle in infected cells, which makes it difficult to resolve many important questions. Meanwhile, cloning full-length genome of HEV is an efficient way to analysis molecular character, viral replication and other problems. Some reports indicated that genotype 4 and genotype 1 were the major genotype in China, though genotype 3 HEV was recently found in swine of Shanghai suburb [13]. Recent observations suggested that the HEV genotype influences the severity of hepatitis $\mathrm{E}$, and that genotype 4 is associated more strongly with the severe form of hepatitis $\mathrm{E}$ than genotype 3 [21]. Therefore, the genomic full-length of the Shanghai isolate was determined in this study for further demonstrating the HEV strain prevalent in eastern China. The full genome of the SH-SW-zs1 isolate was 7265 nucleotides in length and phylogenetic analysis indicated that this isolate belonged to genotype 4 . This isolate closely clustered with isolate DQ450072 and they shared 89.3\% identity(with divergence of $11.3 \%$ ) with each other and represented a distinct subgroup among the genotype 4 isolates with a bootstrap value of $100 \%$, thus suggested that they may come from one common strain. Result of comparison showed that the 3'UTR of this Shanghai isolate was 21-49 bp longer than all the other stains so far avalible on-line. By blast the 21-nt-fragment in GenBank, we found it has many homologous sequences which shared more than $85 \%$ identity with it. So we presumed that this fragment may come from the recombination of genome HEV and its host or other microorganism. The true origin of this short fragment and its specific function need to be further studied. 


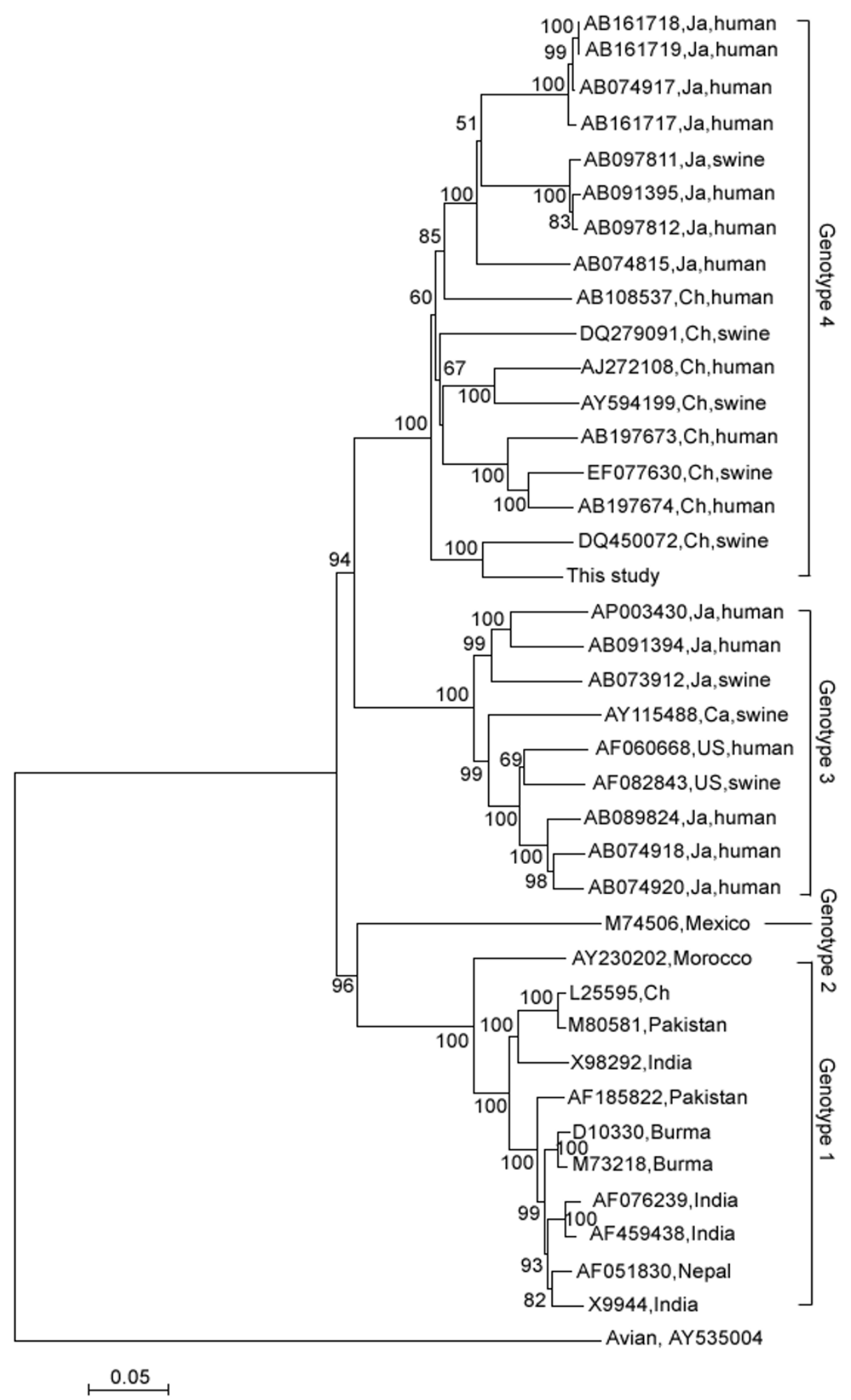

Figure 2

Phylogenetic trees constructed using MEGA software depicting genotypic status of SH-SW-zsI on the basis of full-length genome sequence of $39 \mathrm{HEV}$ isolates. Genbank accession numbers for the full genome were marked at each branch. Percent bootstrap support is indicated at each node. The abbreviations $\mathrm{Ch}$ and Ja stand for China and Japan, respectively. 


\section{Additional material}

\section{Additional file 1}

Comparison of length in the 5'UTR of different HEV stains. The numbers in the brackets show the genotype designation.

Click here for file

[http://www.biomedcentral.com/content/supplementary/1743422X-4-98-S1.tiff]

\section{Acknowledgements}

This study was supported by Key Project of Shanghai Science and Technology Committee of China. (No.06391912).

\section{References}

I. Emerson SU, Purcell RH: Hepatitis E virus[J]. Rev Med Virol 2003, 13(3): I 145-154.

2. Kabrane-Lazizi Y, Zhang M, Purcell RH, Miller KD, Davey RT, Emerson SU: Acute hepatitis caused by a novel strain of hepatitis $E$ virus most closely related to United States strains. J Gen Virol 200I, 82: I687-93.

3. Schlauder GG, Desai SM, Zanetti AR, Tassopoulos NC, Mushahwar IK: Novel hepatitis E virus (HEV) isolates from Europe: evidence for additional genotypes of HEV. I Med Virol 1999 57(3):243-5।.

4. Takahashi M, Nishizawa T, Yoshikawa A, Sato S, Isoda N, Ido K, Sugano $\mathrm{K}$, Okamoto $\mathrm{H}$ : Identification of two distinct genotypes of hepatitis $E$ virus in a Japanese patient with acute hepatitis who had not travelled abroad. J Gen Virol 2002, 83: I 93 I-40.

5. Purcell RH, Emerson SU: Animal models of hepatitis $\mathbf{A}$ and $\mathbf{E}$. ILARJ 200I, 42(2): 16I-I 77.

6. Tam AW, Smith MM, Guerra ME, Huang CC, Bradley DW, Fry KE, Reyes GR: Hepatitis E virus (HEV): molecular cloning and sequencing of the full-length viral genome. Virology |99|, | 85(I):|20-3|.

7. Koonin EV, Gorbalenya AE, Purdy MA, Rozanov MN, Reyes GR, Bradley DW: Computer-assisted assignment of functional domains in the nonstructural polyprotein of hepatitis $E$ virus: delineation of an additional group of positive-strand RNA plant and animal viruses. Proc Natl Acad Sci USA 1992, 89:8259-63.

8. Schlauder GG, Mushahwar IK: Genetic heterogeneity of hepatitis E virus. J Med Virol 200I, 65(2):282-292.

9. Mizuo H, Suzuki K, Takikawa Y, Sugai Y, Tokita H, Akahane Y, Itoh K, Gotanda Y, Takahashi M, Nishizawa T, Okamoto H: Polyphyletic strains of hepatitis $E$ virus are responsible for sporadic cases of acute hepatitis in Japan. I Clin Microbiol 2002, 40:3209-32 I8.

10. Drobeniuc J, Favorov MO, Shapiro CN, Bell BP, Mast EE, Dadu A, Culver D, larovoi P, Robertson BH, Margolis HS: Hepatitis E virus antibody prevalence among persons who work with swine. Infect Dis 200I, 184:I594-I597.

II. Lu L, Li C, Hagedorn CH: Phylogenetic analysis of global hepatitis $E$ virus sequences: genetic diversity, subtypes and zoonosis. Rev Med Virol 2006, 16:5-36.

12. Zheng $Y$, Ge S, Zhang J, Guo Q, Ng MH, Wang F, Xia N, Jiang $\mathrm{Q}$ : Swine as a principal reservoir of hepatitis $E$ virus that infects humans in eastern China. J Infect Dis 2006, 193:1643-1649.

13. Ning H, Niu Z, Yu R, Zhang P, Dong S, Li Z: Identification of genotype 3 hepatitis $E$ virus in fecal samples from a pig farm located in a Shanghai suburb. Vet Microbiol 2007, I 2 1:125-130.

14. Arankalle VA, Chobe LP, Jha J, Chadha MS, Baneriee K, Favorov MO: Aetiology of acute sporadic non-A, non-B hepatitis in western India. J Med Virol 1993, 40:121-125.

15. Kumar S, Tamura K, Nei M: MEGA3: Integrated software for Molecular Evolutionary Genetics Analysis and sequence alignment. Briefings in Bioinformatics 2004, 5: $150-163$.

16. Harrison TJ: Hepatitis E virus-an update. Liver 1999, 19: I7I-I76.

17. Arankalle VA, Chadha MS, Chitambar SD, Walimbe AM, Chobe LP, Gandhe SS: Changing epidemiology of hepatitis A and hepati- tis $\mathbf{E}$ in urban and rural India (1982-98). J Viral Hepat 200I, 8:293-303.

18. van Cuyck-Gandre H, Caudill JD, Zhang HY, Longer CF, Molinie C, Roue R, Deloince R, Coursaget P, Mamouth NN, Buisson Y: Short report: polymerase chain reaction detection of hepatitis $E$ virus in north African fecal samples. Am J Trop Med Hyg 1996, 54: I34- I35.

19. Clayson ET, Shrestha MP, Vaughn DW, Snitbhan R, Shrestha KB, Longer CF, Innis BL: Rates of hepatitis $E$ virus infection and disease among adolescents and adults in Kathmandu, Nepal. J Infect Dis 1997, 176:763-766.

20. Meng XI, Purcell RH, Halbur PG, Lehman JR, Webb DM, Tsareva TS, Haynes JS, Thacker BJ, Emerson SU: A novel virus in swine is closely related to the human hepatitis E virus. Proc Natl Acad Sci USA 1997, 94:9860-9865.

21. Mizuo H, Yazaki Y, Sugawara K, Tsuda F, Takahashi M, Nishizawa T, Okamoto $\mathrm{H}$ : Possible risk factors for the transmission of hepatitis $E$ virus and for the severe form of hepatitis $E$ acquired locally in Hokkaido, Japan. J Med Virol 2005, 76(3):34I-349.
Publish with Bio Med Central and every scientist can read your work free of charge

"BioMed Central will be the most significant development for disseminating the results of biomedical research in our lifetime. "

Sir Paul Nurse, Cancer Research UK

Your research papers will be:

- available free of charge to the entire biomedical community

- peer reviewed and published immediately upon acceptance

- cited in PubMed and archived on PubMed Central

- yours - you keep the copyright 